\title{
Young Women's Experiences Following Discovering a Biological Father in Mpumalanga Province, South Africa
}

\author{
Motlalepule Nathane-Taulela* and Mzikazi Nduna
}

\author{
Department of Social Work, School of Human and Community Development, University of the Witwatersrand, \\ Johannesburg Private Bag 3, Wits 2050, South Africa
}

\begin{abstract}
In South Africa, it has been established that a high number and growing proportion of children are growing up without fathers in their lives. Research suggests that some children who grow up without their biological fathers seek to know them during adolescence. Some discover them whilst others never do. This paper aimed to investigate experiences of young women who discover their fathers during adolescence.

We undertook a qualitative study in the Mpumalanga Province of South Africa to understand experiences of children who grow up with absent fathers. We conducted face-to-face, gender-matched interviews with young women aged 15 to 26 . Five case studies are presented here. We used Topical structural analysis to examine the narratives.

Findings reveal that mother or someone else from the maternal family was instrumental in the disclosure of the father's identity. Four topics that cover the resultant experiences in relation to the father were; a weak or no relationship formed, a positive relationship was formed, the child was disinterested or the mother barred regular visits to the father.

This study concludes that the maternal family context, reasons for father absence, how the disclosure happened influence experiences that follow discovering one's father. Forming a positive relationship with the father depended on the child and father's common interest.
\end{abstract}

Keywords: Absent father, intlawulo, South Africa, undisclosed father, unknown father, young people.

\section{INTRODUCTION}

Research about absent and unknown fathers among young people in South Africa is gaining momentum [1-9]. In a small sample of guardians recruited from a communitybased care centre for orphaned and vulnerable children in a township outside Johannesburg, $31.5 \%$ of respondents reported that they lived with a child under their care who did not know his or her father [10]. As children with absent fathers grow so does their personal awareness of identity, family and kinship and an interest in wanting to know about their absent fathers[4, 7][11].

For some children, unknown and undisclosed paternal identity can be a source of distress, family disharmony and identity confusion $[4,5,7,12]$. In some cases, where children do not know their biological fathers this is due to insurmountable factors such as stranger-rape or the unknown whereabouts of the putative father; however, in other cases, the father and his whereabouts are known to the mother, the maternal family and others but concealed from the child[1315]. Sometimes children embark on their own search and find out about the father; in other cases, the father reappears to claim his fatherhood status[10, 15]. Undisclosed father identity can be an open secret as accounts of accidental disclosures through drunken family members, strangers and

*Address correspondence to this author at the University of the Witwatersrand, Johannesburg Private Bag 3, Wits 2050, South Africa; Tel: +27 11 7174471; Fax:+27 11 7174473; E-mail: Motlalepule.Nathane-Taulela@wits.ac.za also inadvertent involvement in an incestuous relationship are reported [7] .

Discovering one's biological father during adolescence evokes a multitude of experiences. In an Eastern Cape based study distress, behavioral problems, family conflicts and even suicidality reports follow discoveries about biological fathers [7]. At times the child may show little or no interest in their father, especially, when they have a significant father figure such as an uncle or grandfather, or the father may show little or no interest in the child [1]. In family contexts where the child's relationship with their mother and/or maternal family is strained or they suspect that 'knowing' is going to get them into trouble, children pretend not to know, or escape from their mother's family to join the father[7, 15]. In cases of accidental discovery, ambivalent feelings towards the mother are reported with some elements of blaming her for alienating the father [7]. This Eastern Cape based study reports from respondents with subjectively identified psychological distress thus creating an already biased sample. Maladaptive behaviors following discovery were reported in the Eastern Cape study and varied between behavioral problems, delinquency, substance use, distress and suicide attempts[7]. This difference could be a function of the epistemology of these two studies wherein the Eastern Cape study was a study of distress and this current study was presented as a study of understanding the lives of young people who grew up without their fathers.

This article aims to investigate experiences of young women who discover their fathers during adolescence and 
examine the formation of a relationship with the father. We recruited participants from the general population.

\section{METHODS}

We carved this paper from a study conducted in the Mpumalanga Province of South Africa using qualitative research methods as this is an under-researched social phenomena in South Africa[15, 16].

\section{Study Site}

People in this province are multilingual in two or more of the following languages; IsiSwati, isiZulu, isiNdebele, Northern Sotho and Xitsonga with an average household size of 3.65[17]. Households in this province have high father absence: $65.4 \%$ of children under the age of nine were reported not staying with their fathers in 2009[17]. We based the study in a township in the Gert Sibande Municipal District. A district in South Africa refers to an area of jurisdiction of the third sphere of government. This district occupies $2,955 \mathrm{~km}^{2}$ and in the 2001 census, it recorded a population of 221,739 people. Secunda attracts migrant workers from South Africa and the neighboring countries coming to work at the big coal plant. We selected a township outside Secunda as a study site. A township refers to an urban residential area created for black migrant labour, usually beyond the town or city limits[18].

\section{Data Collection}

We employed a Black female fieldworker aged 23, with an Honours degree in Psychology to recruit participants, collect data, translate, and transcribe it. Prior to data collection, we trained her on ethics, data gathering, recruitment strategies, vicarious trauma and interviewing. We developed and wrote the information pamphlets for the study in simple English and distributed them widely in the community. An information sheet handed out to interested volunteers and community stakeholders such as schools, non-governmental organizations (NGOs), social workers, a clinic and youth centers, conveyed a full explanation of the study. We recruited participants through snowballing. Participants constituted a mixture of high school learners, students in higher education institutions, employed and unemployed youth. We insisted on gender-matched interviews to create a comfortable space for respondents and allow for disclosure that is more honest [19]. Data collection occurred in 2011 over three weeks during November/ December.

\section{The Interviews}

Interviews were conversational and guided by a set of open-ended questions formulated in advance and outlined in an interview schedule. We questioned the participants in their home language. The interview started with a general question asking each respondent to tell the interviewer why he or she agreed to participate in the study. Depending on their story, appropriate probing followed. We used the Timeline technique to aid with probing and to help the respondents recall events and experiences[20]. The SAD Persons Scale was selectively administered at the end of the interview with participants who displayed a strong negative emotional reaction or distress[21]. This formed the basis for recommending a referral to the local social workers for counseling. Largely participants were not enthusiastic about referral. This is consistent with reports in other similar studies [4, 22]. Each interview lasted between 40 minutes and an hour. More information on the fieldworker training, recruitment of participants, data collection, interviewing, and debriefing is discussed in other reports[8, 23, 24].

\section{Data Analysis}

The same field worker transcribed and translated the audio-recorded interviews into English. An independent researcher verified the translation. Transcripts varied in length from seven to twenty-five pages reflecting the varied lengths of the interviews. Transcripts were read and re-read independently for data exploration and picking up the trend of narratives presented [25]. The transcripts showed that participants had varied experiences with father absence; these are discussed elsewhere[8, 15, 26]. A sub-story within the bigger narrative about discovering one's father during adolescence sparked the interest for this paper. We included five cases where the participants met or came to know about their absent fathers in the analysis for this paper. Exclusion of some participants happened because they always knew their absent fathers or the absence was due to death or the father was still unknown at the time of the interview.

Topical structural analysis was used [27]. Major topics and identified sub-topics formed the basis for the division of each transcript. The list of main topics and subtopics served as a map of each transcript and we pulled the subtopic of discovering one's father. The researchers had to find and make the connections during data analysis, as the participants did not convey the stories in a linear manner. The research question that reported experiences of discovering a putative father during adolescence guided the analysis. Within the sub-story of discovering one's father, we examined the structural components that go into minimal definition of a story and summarised the following: setting, action aimed at attaining a goal and an outcome. The 'setting' refers to what the participant knew prior to the interview about their absent father. Action referrs to what the participant did to discover her father. An outcome refers to what happened beyond the discovery.

\section{Participants}

Of the selected cases, two were in grade 9, two in grade 12 and for one there was no record of her grade. Three of the selected participants were raised by the maternal grandmother, one (Cindy) by her parents and for one (Portia) it was unclear. In Cindy's case, the word parent is in italics to signify that there is an issue with this. This discussion follows later in the presentation of Cindy's case. Sometimes the mother was unemployed, a migrant labourer, or deceased; leaving participants financially dependent on the extended family, older siblings and social grants. Some participants indicated that they lived with ailing parents and or guardians who abused alcohol in attempting to emphasise their difficult and unstable lives and growing up in dysfunctional homes. The number of siblings in the participants' families (including the participants) ranged between two to seven, and half of the participants had stepbrothers and sisters. These are socio-economic problems reflective of communities in Mpumalanga [17]. 
At the time of the interview, some participants did not physically know their biological father, others had seen photos of him, whilst others had an opportunity to meet and know him. The absence of the father was due to a variety of reasons, chief amongst that was the disappearance of the father when the mother was pregnant or outright rejection of paternal responsibility, or in cases of migrant workers he migrated back to his hometown or country. In a few cases, participants did not know exactly what happened between their mothers and the biological fathers and what led to them not knowing their fathers.

\section{Ethical Considerations}

The University of the Witwatersrand's ethics Committee for Research with Human Subjects granted Ethics approval for this study. All participants signed a consent form and gave permission for an audio-recorded interview. Each participant received R50.00 (US \$5.7 in 2012) as reimbursement for costs incurred in partaking in the research. While monetary incentives may motivate volunteers to participate in research, we do not think this small amount unduly induced volunteers[28-30]. We deleted all audio recordings from the recorders and saved them in a password-protected file in the first author's computer. We replaced participants' names with pseudonyms to protect their identities. We held a member-checking workshop to present preliminary findings and discuss their correctness with an audience that comprised thirty young people including some who were interviewed [31]. Attendees commented on whether interpretations of the findings were correct.

\section{Findings}

Participants discovered their absent fathers in various ways. Three of the five participants reported asking about their father. They asked the mother or maternal elders. Asking was a process and when they asked, they did not always receive a positive response or correct information. Parents' responses to being asked about paternity can be evasive and negative[13-15].

For others, someone else from the maternal family disclosed willingly, or accidental disclosure occurred. The other two cases it was their mothers who voluntarily disclosed the information about the absent father and explained the circumstances that led to father absence. The next section presents findings from the topical structural analysis based on five case studies. The participant's age is in brackets.

\section{Tsakane (16)}

\section{The Setting}

Tsakane lived with her maternal uncle. She occasionally visited her biological mother who lived in a different section with her husband and their children. In her interview, she disclosed that she met her father for the first time two years prior to the interview when she was 14 years old. Her father worked and lived in Johannesburg. His parents and other family members lived in the same street as Tsakane's maternal family. All along, she knew the biological father's family but was not aware that they were her relatives.

\section{Action Aimed at Attaining a Goal}

Tsakane's mother introduced her to the biological father without her having ever asked. Before personally meeting her father, Tsakane reported that she knew about her father through some of the things that her mother and other elders in the family said. She gathered that there was some animosity between her absent father and her mother, based on the negative things said. She said her mother, "...used to tell me bad things about him, like he doesn't know how much Pamper's (baby's diapers) costs... he has never bought you anything..." It would appear that her mother was resentful towards her father for being irresponsible but then she voluntary told her about him and showed Tsakane her father. Her mother did not plan the introduction as it happened while they walked down the street. Her mother unexpectedly pointed out a man who was painting a house and said to Tsakane, "...there is your father go and greet him..." (Pointing and gesturing). In keeping with this, throughout the interview Tsakane described her biological father as someone who suddenly appeared. In this context, where they lived in the same neighborhood, one could argue the inevitability of this discovery and to some extent the possibility that she would inevitably find out placed undue pressure on her mother. The participant said she went and introduced herself while her mother waited at a distance.

\section{The Outcome}

After meeting her biological father Tsakane realised that the absent father's family knew her all along. She occasionally played with children from that home oblivious that they were her relatives. Tsakane's meeting with her biological father did not please her maternal family. Her uncles did not allow her to form a relationship with her father or to visit him; citing his failure to pay Intlawulo $^{I}$ and perform traditional rituals to acknowledge paternity as a prohibition. When she showed interests in him and his family Tsakane said her mother discouraged her saying, "...he has never done anything for me..."

\section{Portia (15)}

\section{The Setting}

Portia was in grade 9 at the time of the interview. In the opening of the interview, Portia said she did not know her father but in the same interview reported that she stayed with him the year before the interview. It became clearer as the interview unfolded that the participant grew up not knowing her father save for identifying him through pictures.

\section{Action Aimed at Attaining a Goal}

During preparations for her mother's burial, she discovered and reunited with him. This was about two years prior to the interview. He came home and stayed with them for a few days but disappeared again. The participant used the language, "...I found him..." Portia did not ask around

\footnotetext{
${ }^{1}$ In African cultures, the term intlawulo sometimes called 'damages' refers to a fine imposed in reparation for an offense that has been committed especially when a man impregnates a woman out of wedlock. The fine has to be paid to the woman's family, in order to make reparations for having offended and disrespected them by impregnating a woman out of wedlock. In certain cases, a family may choose not to recognize the man as the father of the child if the fine is not paid. Similarly, it may be decided that the child will not carry the man's surname if damages are not paid (Mavhungu, 2013).
} 
for her father and when he came back home she was happy for his return but had questions for him.

\section{The Outcome}

After a few days, Portia's father abandoned her. Portia believed that it was because she asked him to explain his absence in their life prior to her mother's death. This must have upset him.

\section{Tsholofelo (18)}

\section{The Setting}

Tsholofelo and her siblings lived with their maternal uncle, his wife and their children. As a child belonging to that family they met all her basic needs and treated her well and fairly. At the time of the interview, she had not met her father and she did not display interest. We included her transcript in the analysis because she found out about her father.

\section{Action Aimed at Attaining a Goal}

Tsholofelo's mother died when she was still young and at the time, it never occurred to her to ask her mother about her absent father. Tsholofelo's older cousin who grew up with Tsholofelo's mother was very close to her. This cousin knew Tsholofelo's biological father and often this cousin, her grandmother and some relatives spoke about how she looked like her father. The cousin offered help and suggested that they look for the biological father so that Tsholofelo can know her father and her real surname. Tsholofelo declined this offer stating that her biological father must look for her as he is the one who left her.

\section{The Outcome}

The participant had no interest in meeting her father even though there seemed to be an opportunity for her to meet him. Tsholofelo reported that her life was fine as it was as her maternal uncle and his family loved and cared for her. She said, “...I wouldn't think that I would say that I need him in my life. Do you understand? Because maybe if he was here, maybe I would not be as happy as I am today, you see. I think he did me a favour by not being in my life. Because I do have a father and I am happy..." Tsholofelo felt that the absent father made a choice of leaving and as an adult; he should be the one looking for her and not the other way round.

\section{Nokwazi (18)}

\section{The Setting}

Nokwazi said she was told that her father was a migrant worker from Swaziland and he had a family and children there. To the best of her knowledge, her father never acknowledged paternity and he left town when Nokwazi's mother was pregnant with her.

\section{Action Aimed at Attaining a Goal}

Nokwazi initiated the talk and asked about her absent father upon realising that she was using her mother's surname, which she referred to as not her real surname. She wanted to know who she was and where she came from. Nokwazi said in her case, “...when I was 7 years I used to ask my mom about my dad, and she did tell me what happened but you could see that it is also painful to her... 'Her mother gave her some information and she took the initiative of searching for her father with the help of her mother and her aunt's husband. The aunt's husband was able to trace the father and made arrangements for the two of them to meet at some traditional ceremony at the aunt's house. Nokwazi said, “...you know I didn't know my father but one day he came and they [maternal guardians] told me there is your father and I started to want to be close with him and bond with him, so that we can get to know each other. And I would visit him...you see so I told myself that I will go to him and we will have a normal conversation... "Nokwazi'sfather had his own family, he later introduced her to the siblings, and she talked about feeling welcome.

\section{The Outcome}

After meeting her father, Nokwazi asked her mother for permission to change her surname and take her father's surname. Her mother granted her permission to talk to the father and explained the rituals that they had to perform before the changing of surnames. The unemployed father did not have the money to pay for all the things required to perform the rituals. After reconnecting with her father, she said, "... the way things are, he does show that he does care. He is the one who guides me in everything, so I can see that if I found this person on time, I would have been a better person. Because even now I have changed, my life has changed because of him. Therefore, you see he is a caring person. He has this thing that he can guide you, he can give you an idea on your success... "The participant went on to explain how her life was different and better with her father in her life, saying "... and his family they have this thing you know I now have this and that I want to do this, he is the one even now as I am going to university as I said, he is the one who wanted to discover which one will be fine which course everything. He was involved in my education, and I can see how important he is..."

\section{Cindy (18)}

\section{The Setting}

Cindy grew up with her parents and siblings albeit she was oblivious to the fact that the man she considered her elder brother was in fact her father. She found out the truth when her 'mother' passed away. (Cindy's mother was in fact her paternal grandmother).

\section{Action Aimed at Attaining a Goal}

During preparations for her mother's burial Cindy learnt, in the midst of a family conflict and a row that actually the woman they were burying was not her mother but her grandmother. She was a mother to her 'eldest brother' who in fact was her biological father. When her big brother (real biological father) impregnated his girlfriend (Cindy's unknown mother) they were still young and his mother took the child, Cindy, and raised her as her own.

\section{The Outcome}

The resolution of this discovery was unclear. What transpired from the narrative was that Cindy continued to live with her father (now step-grandfather) as before. 


\section{DISCUSSION}

This paper aimed to investigate experiences of young women who discovered their fathers during adolescence. Using topical structural analysis, the study details the setting of each participant, actions taken by the participants to find and know their father and the outcomes of these actions. Each case study is distinct and yet two overarching themes summarise the interconnections. One of the participants presented here had not met her father but she was not completely ignorant of his identity. This is in agreement with other findings that children who do not know their fathers may know some information about them, they are not always completely uninformed $[1,8,32][33]$. The mere existence of one's biological father incites curiosity in young people to want to know him. Discovering information about an absent father increases an interest in finding and knowing him. As one of the cases demonstrated that for a young woman who received support from her mother this seemed to have made the processes of discovery and connecting with her father easier. This is contrary to a situation where the child searches on her own and sometimes without the awareness and approval of the mother[7]. This suggests that maternal support may be important in helping children negotiate the discovery of their fathers.

The first theme discusses indifference; the second discusses the forming of a relationship with the father.

\section{INDIFFERENCE}

Not all the narratives ended with a clear resolution of a relationship formed following the discovery of a father.

This paper addresses the question of what makes some young women interested and others indifferent when they discover their unknown absent fathers. The disconnection between the ideal father and the reality of the father who remains absent after they had been introduced could create a challenge of unmet expectations for children. Research findings suggest that when the mother provides for the child and fulfills the father's role, and when the absent father phenomenon is normalised the child may lose interest and not ask about the absent father[15]. It is unclear whether gender plays a part, whether it depends on socio-economic status, whether it reflects young people's defiance or whether it reflects satisfaction with a social father who could be an uncle, grandfather, or other who adequately cares for a family.

In cases such as Tsholofelo and Cindy's, they remained indifferent after they found out about their absent fathers. The role of social fathers such as uncles, grandfathers, stepfathers or mother's boyfriends is discussed in previous publications $[1,3,9,34,35]$. Here too it would seem that a participant who had a strong maternal uncle who played a positive role as a social father and provided both financially and emotionally became indifferent to knowing her biological father. This observation confirms that of the response of other children in similar situations where they report lack of interest in their fathers.

\section{Relationship with the Father}

Local and international literature reports that young people yearn for relationships with their fathers. It is no wonder that studies such as those conducted by Lesch in the Western Cape, priorities the relationship between father and daughter[36]. This current study coming from a Black African community once more confirms that this relationship is important hence, the forging of some positive relationships with fathers following the discovery. Young women, as uncovered here, would love to know more about their fathers and have a relationship with him. Nevertheless, extended maternal family may interfere with this newly found relationship and interpret it as a betrayal and abandonment. Pursuance of the child's individual need to connect with the putative father may create tensions within the maternal family wherein they see the young women's interest as a selfish, individualistic act of defiance. An African familial context expects young people to not go against parents' wishes. Doing so might cause wrath. This is discussed in studies of silence as a strategy for personal safety and family honour $[15,22]$.

It seems like an important issue that taking one's father's surname will mean that one has found their true identity[26]. In Nokwazi'scase, her mother did not have a problem with her child taking her father's name as long as the father performed some rituals to acknowledge paternity. According to Nsamenang [37], in the African 'traditional' context children normatively take the father's identity and need to have certain rituals performed according to their biological father's clan name. Knowing one's lineage, roots and identity in relation to the father's side of the family is central and significant to a child's future and well-being[12]. So, even among these young people discovering who their father was and taking on their fathers surname would have meant that they have found their identity which is central to their roots and lineage[26]. However, it is difficult to analyse the quality of these relationships because the men were not staying with the participants and parented from a distance. What makes it even more difficult is that the child-father relationship in this setting is denoted by either material provisions or the father being a visibly authoritarian parent who disciplines, corrects and ensures order in the house[1, 6], so because they were not staying with them it was not possible to learn in-depth about how things unfolded.

Feelings of ambivalence, suppression and repression were reportedly fostered by the mothers or maternal guardians in children. We had no evidence of a positive outcome in our findings, especially, when the participants' mother was unhappy about her daughter forging a relationship with her father. Prolonged conflict between the mother and the father prevented the young women from fully connecting with their fathers. It appeared from the data that unresolved conflict between the father and the mother complicated a relationship as sometimes the mother and the maternal family discouraged contact. For instance, where no 'intlawulo' featured it resulted in difficult access to a child and changing of a surname can only happen after the fulfilment of this custom. A father's unemployment is one of the challenges in this regard because as such he cannot organise the ceremony due to financial constraints. For example, the unemployment rate in Embalenhle, which falls under Gert Sibande local municipality, is 29.4 percent, and recorded the third highest strict unemployment rate among the nine provinces[38]. The expanded unemployment rate was 43.4 percent in the first quarter of 2013 [38]. 
We need to understand the common conflict between the paternal and the maternal families within the socio-cultural and economic circumstances. Identity for children born-outof wedlock remains maternal unless the father acknowledges paternity, offers 'intlawulo' and introduces the child to their ancestors through traditional ways. In some cases even when these are met the child remains with the maternal family and uses her maternal surname but they will have a relationship. Absent fathers is a common phenomenon in children born out-of-wedlock and with this comes unresolved relationship break-up, conflict and feelings of betrayal. Following the break-up the mother raises the child single-handedly and in the context where most single mothers hold precarious jobs and earn little wages mothers may feel pain in raising the child without the support of the father. These are reported as sore points in maternal non-disclosure of biological fathers [9] [13, 14, 39, 40].

Macro-level factors such as the initial response of the putative father on hearing the news of the pregnancy influence how children negotiate the discovery. If he denied or evaded, a conflict ensued. It was unclear in this study, as in other studies, whether the putative fathers lacked the finance to honour the 'intlawulo' or whether they protested the 'custom' of pledging 'intlawulo' $[41,42]$. Either way, when a man does not pay 'intlawulo' he may not have access to the child [43]. In typical situations, even after the participant found their father, a relationship was not always easy to forge if he never paid 'intlawulo'; the maternal family contested access on the basis that he owed them. Consequently, the child is caught between adults and two families who are in conflict, thus barring a child from forming any form of connection with the father. This clearly takes away the child's agency to act on her own in relation to her father. Factors beyond them influence how children negotiate the discovery of their biological fathers and their family's views about their father play a very crucial role. This is the case with withheld paternal identity disclosure.

Young people may somehow idealise an absent father. This was evident in the cases of the participants who reconnected with their fathers. They strongly felt that if their fathers were present in their lives they would have been better off. Some view this as a denigration of the role played by the mother and the idealisation of the father. A study conducted in Alexandra Township where adolescent boys spoke highly about their fathers and believed that their lives would be better off if the father was present also reported this idealisation of the father[4].

Children's reactions to incidental disclosure of biological father warrants further research and interventions to help the child. In this study, we saw no evidence of maladaptive behaviours following discovery of one's father.

\section{STUDY LIMITATIONS}

There was only one interview per participant and during data analysis; it became clear that we could have filled some gaps with a second interview. The interviews elicited narratives from participants and because telling one's story depends on memory this data could be fallible to limitations of memory. Memory depends on the context and time and when a participant is in a different context they may remember some things differently, hence these findings are not complete representations. We must take into account this instability and fallibility of memory when reading these findings. Sometimes in narrative interviews, especially in sensitive and painful subjects such as unknown fathers, there may be suppression of memory serving as a protective mechanism against re-experiencing trauma. We recommend that future studies perhaps hold a second round of interviews to allow participants to fill in information gaps. Alternatively, one should interview dyads of mothers and children to get more information.

\section{CONCLUSION}

This paper presented experiences of young women who discover their fathers during adolescence. The findings of this study indicate that maternal grandmothers played an important role in the upbringing of their grandchildren. The study concludes that mothers were instrumental in giving information leading to the discovery of the absent father. The role of culture, performing rituals to acknowledge paternity and unmet cultural expectations can be seen as the core that determine whether a child will be barred from forming any relationship with the biological father or not. From the participants point of view a father was more than a provider as there was a yearning from some of the participants to connect with their fathers, form some kind of a relationship, and get to know them better.

\section{CONFLICT OF INTEREST}

The authors confirm that this article content has no conflict of interest.

\section{ACKNOWLEDGEMENTS}

We would like to express our gratitude to the XXXICP2012 for the CHANGE Fellowship fund, the Jacobs Foundation, the National Research Foundation of South Africa and IUPsyS. We thank the study participants for their time and contribution of data. We would like to thank members of the Father Connections research team, Grace Khunou, Yandisa Sikweyiya, Thandeka Mdletshe, Vuyani Pambo, Tidimalo Padi, and Priscilla Gerrand for their support in the execution of this study.

\section{REFERENCES}

[1] Clowes L, Ratele K, Shefer T. Who needs a father? South African men reflect on being fatheredJGender Stud 2013; doi: 10.1080/09589236.2012.708823.

[2] Denis P, Ntsimane R. Absent fathers: why men don't feature in stories of familes affected by HIV/AIDS in Kwazulu-Natal?In: Richter L, Morrell R, Eds. Baba: Men and Fatherhood in South Africa. Cape Town: HSRC Press2006; pp. 237-49.

[3] Holborn L. Fractured families: A crisis for South Africa. SAIIR Fast Facts 2011b; 4: 2 .

[4] Langa M. Adolescent boys' talk about absent fathers. J Psychol Afr 2010; 20(4): 519-26

[5] Phaswana ED. Experiences of rural Black South African adolescents who never met their own biological fathers. Magister Educationis Mini-Dissertation. Rand Afrikaans University, Johannesburg 2003.

[6] Mavungu EM, Thomson-de Boor H, Mphaka, K. "So we are ATM fathers": A study of absent fathers in Johannesburg, South Africa. Johannesburg: Centre for Social Development in Africa, University of Johannebsurg 2013.

[7] Nduna M, Jewkes, R. Undisclosed paternal identity in narratives of distress among young people in the Eastern Cape, South Africa. J Child Family Stud 2011b; 20(3): 303-10. 
[8] Padi T, Nduna M, Khunou G, Kholopane P. Defining absent, unknown and undisclosed fathers in the lives of young people in South Africa. Soc Rev South Afr 2014; 45(2): 44-59.

[9] Holborn L, Eddy G. First Steps to Healing the South African Family. IRR 2011.

[10] Nduna M, Kasese-Hara M, Ndebele M, Pillay N. Prevalence and Characteristics of Unresolved Paternal Identity in Families of a South African Community. J Psychol Afr 2011; 21(4): 589-94.

[11] Datta K. "In the eyes of a child, a father is everything": Changing constructions of fatherhood in urban Botswana.Women's Stud Int Forum 2007; 30(2): 97-113.

[12] Meerum Terwogt M, Meerum Terwogt-Reijnders CJ, van Hekken, SMJ. Identity problems related to an absent genetic father. Zeitschrift fur Familienfirschung 2002; 14(3): 257-71.

[13] Nduna M. Factors that hinder the disclosure of the biological identity of a father to a child: South African mothers' perspective. J Femin Fam Ther (In Press).

[14] Manyatshe L, Nduna, M. "Secret keeping: Mother's concerns in dealing with undisclosed biological paternity of their child in Johannesburg, South Africa”. Gender Questions 2014;2(1): (in press).

[15] Nduna M, Sikweyiya Y. Silence from young women's narratives of absent, unknown and undisclosed fathers from Mpumalanga, South Africa. J Child Fam Stud 2013; doi: 10.1007/s10826-013-9866-3

[16] Hennink M, Hutter I, Bailey A. Qualitative research methods. LosAngeles: Sage Publications 2011.

[17] Makiwane MB, Makoae M, Botsis, H, Vawda M. A baseline study on families in Mpumalanga. Human Sciences Research Council, Pretoria: Human and Social Development, Population Health, Health Systems and Innovation, CeSTii 2012

[18] Statistics South Africa: Census. Concepts and definitions. 2004; Vol. 2: Statistics South Africa Private Bag X44, Pretoria 0001.

[19] Jewkes R, Nduna M, Levin J, Jama N, et al. A cluster randomizedcontrolled trial to determine the effectiveness of Stepping Stones in preventing HIV infections and promoting safer sexual behaviour amongst youth in the rural Eastern Cape, South Africa: trial design, methods and baseline findings. Tropic Med Int Health 2006; 11(1): 3-16.

[20] Berends L. Embracing the visual: using timelines with in-depth interviews on substance use and treatment. Qual Rep 2011; 16(1): $1-9$.

[21] Patterson W, Dohn H, Bird J,Patterson G. Suicide Assessment: SAD PERSONS. Psychsomatics 1983; 24: 343-9.

[22] Nduna M, Jewkes, R. Silence: A strategy to deal with psychological distress among young people in the Eastern Cape, South Africa. Vulnerable Child Youth Stud 2011a; 6(4): 360-72.

[23] Nduna M, Khunou G, Sikweyiya Y, Pambo V, Mdletshe T. Vicarious and Secondary Trauma in Interviews on Father Identity and Connections. In: Nakray K, Alston M, Whittenbury K, Eds. Social Science Research Ethics for a Globalizing World: Interdisciplinary and Cross-Cultural Perspectives: Routledge 2014.

[24] Nduna M, Sikweyiya Y, Khunou G, Pambo V, Mdletshe T. Ethical Reflections in Qualitative Research on Father's Absence: A South African Township Case-Study. In: Nakray K, Alston M, Whittenbury K, Eds. Social Science Research Ethics for a
Globalizing World: Interdisciplinary and Cross-Cultural Perspectives: Routledge 2014.

[25] Sands RG. Narrative Analysis: A feminist approach. In: Padgett DK Ed. The Qualitative Research Experience. Toronto: Thomson, Brooks/Cole 2011; pp. 48-78.

[26] Nduna M. Growing up without a father and a pursuit for the right surname. Open Fam Stud J 2014; 6(Suppl 1): (in Press).

[27] Nduna M, Jewkes R. Denied and disputed paternity in teenage pregnancy: topical structural analysis of case studies of young women from the Eastern Cape Province. Soc Dyn 2012; 38(2): 314-30.

[28] Emanuel EJ. Ending concerns about undue inducement.J Law Med Ethics 2004; 32: 100-5.

[29] Grady C. Money for research participation: Does it jeopardize informed consent? Am J Bioethics 2001; 1(2): 40-4

[30] Jewkes R, Sikweyiya Y, Nduna M, Shai JN, Dunkle K Motivations for, and perceptions and experiences of participating in, a cluster randomised controlled trial of a HIV-behavioural intervention in rural South Africa. Culture Health Sex 2012; doi: 10.1080/13691058.2012.717305.

[31] Lyons HZ, Bike DH, Johnson A, Bethea A. Culturally competent qualitative research with people of African descent. J Black Psychol 2011; doi: 10.1177/0095798411414019.

[32] Jago BJ. A primary act of imagination: an autoethnography of father-absence. Qual Inq 2006; 12(2): 398-426.

[33] Polela M. My father, my monster: A true story. Auckland Park, Johhanesburg: Jacana Media 2011.

[34] Mkhize N. African traditions and the social, economic and moral dimensions of fatherhood. Baba: Men and Fatherhood in South Africa. Cape Town, South Africa: HSRC Press 2006; pp. 183-98.

[35] Holborn L. Broken families breaking youth. Fast Facts. IRR $2011 \mathrm{a}$; 5: 2-11.

[36] Lesch E, Ismail A. Constraining Constructions: Low-income Fathers' Perceptions of fathering their Adolescent Daughters. Open Fam Stud J 2014; 6(Suppl 1): In Press

[37] Nsamenang AB. Fathers, family and wellbeing in Cameroon: a review of literature. National Centers on Fathers and Families: Philadelphia: University of Pennsylvania 2000.

[38] Statistics South Africa: Census. Socio-Economic Review Outlook Mpumalanga 2013

[39] Manyatshe L, Nduna M. Maternal non-disclosure of a child's biological father: Methodological reflections from a Johannesburg study. New Voices 2014; 10(1): 35-52.

[40] Manyatshe L. Why mothers won't tell: Narratives of factors that influence maternal non-disclosure of biological paternal identity. University of the Witwatersrand: Johannesburg 2013.

[41] Khunou G. Paying your way and playing with the girls. S A Labour 2008; 31(5): 48-50.

[42] Bank LJ. Home spaces, street styles: contesting power and identity in a South African city. New York and Johannesburg: PlutoPress and Wits University Press 2011.

[43] Chili S. Perspectives and experiences of fatherhood among young people: a case study of 'Black' students in Durban, KwaZulu Natal. Masters of Population Studies. University of KwaZulu-Natal 2012.

This is an open access article licensed under the terms of the Creative Commons Attribution Non-Commercial License (http://creativecommons.org/licenses/ by-nc/3.0/) which permits unrestricted, non-commercial use, distribution and reproduction in any medium, provided the work is properly cited. 